\title{
Parques verdes urbanos: espaços de sensibilização ambiental e bem- estar social
}

Os Parques Verdes Urbanos são espaços destinados à proteção do ambiente natural e bem-estar psicossocial para a população de grandes cidades. Diante dessas funções, esse estudo de caráter qualitativo, investigou os tipos de usos sociais e a percepção ambiental de frequentadores de um Parque Verde Urbano (PVU), na cidade de Manaus-AM. Participaram da pesquisa 30 adultos, a partir da aplicação de entrevistas semiestruturadas logo após a visita ao parque. Os resultados apontam que as pessoas se deslocam para este espaço em busca de contato com a natureza, bem-estar e lazer. O estudo mostra que as percepções ambientais dos visitantes sobre o PVU evidenciam aspectos relacionados à sua atratividade, sentimentos de prazer e valorização da natureza além de despertar pensamentos relacionados à conservação da natureza. Constatou-se que a percepção ambiental dos visitantes incorpora de forma contundente aspectos ambientais que levam ao bemestar e estes aspectos socioambientais dão suporte ao caráter de importância do PVU. Dessa forma, os espaços se configuram como instrumentos de sensibilização das pessoas para a proteção da natureza e espaços sociais de socialização.

Palavras-chave: Conservação Ambiental; Parques verdes Urbanos; Percepção Ambiental.

\section{Urban green parks: space for environmental awareness and social well-being}

\begin{abstract}
The Urban Green Parks are spaces destined to the protection of the natural environment and psychosocial well-being for the population of big cities. Given these functions, this qualitative study investigated the types of social uses and the environmental perception of visitors of an Urban Green Park (UGP), in the city of Manaus-AM. Thirty adults participated in the study, from the application of semistructured interviews shortly after the visit to the park. The results indicate that people move to this area looking for contact with nature, well-being and leisure. The study shows that the environmental perceptions of the visitors about the UGP show aspects related to their attractiveness, feelings of pleasure and appreciation of nature besides raising thoughts related to the conservation of nature. It was verified that the environmental perception of the visitors strongly incorporates environmental aspects that lead to well-being and these socio-environmental aspects support the importance of the UGP. Therefore, spaces are configured as tools to raise awareness of people for the protection of nature and social spaces of socialization.
\end{abstract}

Keywords: Environmental Conservation; Green Urban Parks; Environmental Perception.

\section{Topic: Conservação da Biodiversidade}

Reviewed anonymously in the process of blind peer.

Karoline Matos Fernandes (i)

Universidade Federal do Amazonas, Brasil

http://lattes.cnpq.br/0342818490919268

http://orcid.org/0000-0003-3969-5957

karolmfernandes@yahoo.com

Maria Inês Gasparetto Higuchi (iD

Brunel University London, Inglaterra

http://lattes.cnpq.br/8607852207828061

http://orcid.org/0000-0001-6525-4018

higuchi.mig@gmail.com
Received: 04/07/2017

Approved: 05/10/2017

\section{Referencing this:}

FERNANDES, K. M.; HIGUCHI, M. I. G.. Parques verdes urbanos: espaços de sensibilização ambiental e bem-estar social. Revista IberoAmericana de Ciências Ambientais, v.8, n.4, p.23-36, 2017. DOI: http://doi.org/10.6008/SPC2179-6858.2017.004.0003 


\section{INTRODUÇÃO}

Parques Verdes Urbanos (PVU) é uma denominação recente e nem sempre clara, uma vez que se trata de um lugar onde há prevalência de elementos da natureza sobre aqueles construídos. Muito se discute sobre o que seriam esses elementos naturais, se vegetação nativa ou plantada e cuidada, mas tais aspectos não apresentam um consenso além da destacada área verde. Porém, se na definição não há consenso, sua destinação e importância é compartilhada pela grande maioria dos profissionais.

Os PVUs são importantes para a qualidade de vida ambiental e social nas cidades e surgem para minimizar os efeitos ambientais e sociais próprios do ambiente citadino. Em primeiro lugar, as cidades se tornaram ambientes pouco saudáveis para seus habitantes. Com o adensamento das construções num espaço restrito, as grandes cidades não atendem com efetividade a um conforto e qualidade ambiental aos seus ocupantes. Em segundo lugar, os citadinos enclausurados nas grandes cidades vivem sob stress contínuo da vida urbana atribulada. Em ambos os casos, a natureza foi sendo ocupada pelas construções, de modo a ser quase expulsa do ambiente urbano para dar lugar às necessidades prementes da vida moderna: agilidade e tecnologias.

Recentemente, as ciências ambientais e sociais têm destacado os malefícios desse estilo de vida que a sociedade está envolvida. Como forma de mitigar tais problemas, os PVUs têm sido identificados como áreas passíveis de contemplar um equilíbrio tanto ambiental quanto social. Embora os PVUs não possam ser reconhecidos como genuínos espaços de natureza rústica, em sua forma pura e nativa, esses contêm em sua configuração áreas verdes que são compartilhadas com áreas construídas, seja para o lazer, entretenimento ou educação, e sobretudo como aspecto de conservação ambiental.

Os PVUs são resultados da ação humana, pois contêm um componente natural e outro sociocultural que reflete os costumes e tradições da sociedade (GARCIA, 2005). Além disso, servem como uma área necessária para a saúde integral das pessoas além de contribuir para o equilíbrio do ecossistema. Têm, portanto, a função de amenizar as tensões da vida moderna (BROWNE et al.,1973). Atualmente os PVUs representam um espaço de errância (FISCHER, 1994), isto é, um espaço capaz de proporcionar liberdade às pessoas.

A busca por um ambiente agradável e prazeroso é uma constante humana, e encontra nos PVUs uma resposta a essa demanda. Mesmo com todas as potencialidades, os PVUs nem sempre são utilizados de acordo com as propostas da sua criação. Vários motivos levam a população usar esse espaço com pouca frequência. Aspectos próprios das pessoas, a cultura e a escalada da violência comprometem o uso saudável dos PVU. O bom aproveitamento dos espaços verdes, nas cidades, poderia dar aos $80 \%$ da população mundial um alívio das tensões citadinas e a busca do encontro com o ar fresco, os ruídos do campo e o encontro com mundo natural, portanto, qualidade de vida (RIBEIRO, 2000).

Entretanto, como aponta Segawa (1996), a natureza, as paisagens, os jardins públicos, nada significam em si mesmo. São as pessoas que atribuem significados que vão qualificar as imagens e os objetos presentes num lugar. A conquista do espaço urbano pelas pessoas é uma importante conquista social e os 
PVUs, espaços públicos indispensáveis para o dinamismo da cidade, devem atender as demandas do seu tempo, seja social ou ambiental (MEUNIER, 2009).

Para se compreender esses significados, a perspectiva da Percepção Ambiental é um caminho profícuo. As percepções que uma pessoa possui sobre em um determinado lugar está ancorada em vários fatores pessoais (racionalidades e afetividades; gênero, escolaridade, idade, etc.), culturais (valores, crenças, costumes) bem como aspectos contextuais (características do ambiente físico, recursos ali presentes, temperatura, o relevo, paisagem e o arranjo espacial, entre outros). Além disso, o estudo da percepção ambiental é de fundamental importância para se compreender melhor as inter-relações entre o ser humano e o ambiente, suas expectativas, anseios, satisfações e insatisfações, julgamentos e condutas.

Assim, para se compreender a importância atribuída ao papel social dos PVUs, aliada aos serviços ambientais e urbanísticos, este estudo apresenta uma realidade vivida na cidade de Manaus-Am. O objetivo foi analisar os usos sociais e a percepção ambiental de frequentadores do Parque Municipal do Mindu, administrado pela Secretaria Municipal do Meio Ambiente e Sustentabilidade. Estão ainda problematizados nesse estudo, as implicações na construção do cenário de proteção da natureza, a partir da caracterização dos tipos de atividades estimuladas e desenvolvidas, e os sentimentos vivenciados no âmbito do Mindu.

\section{Parques Verdes Urbanos: funções ambientais e sociais}

Os espaços verdes, como os PVUs, no ambiente urbano, constituem espaços com dupla função: ambiental e social (GARCIA et al., 2006). Esses espaços contribuem para amenizar problemas de aspectos ambientais vividos pelas grandes cidades, como: influenciam no microclima ao propiciar temperatura amena, aumento da umidade relativa do ar, absorção de poluentes, minimizam a poluição sonora e visual; harmonizam a paisagem urbana; contribuem na organização dos espaços urbanos e no auxílio da captação das águas pluviais; diminuem a amplitude térmica, mantem a permeabilidade e a fertilidade do solo e proporciona abrigo a fauna e flora existente (ROMERO, 1999; COSTA et al., 2006; OLIVEIRA et al., 2007). Configuram-se, portanto, de grande importância para a manutenção de algumas características ambientais favoráveis para a qualidade de vida das pessoas nas grandes cidades

Uma visita aos parques representa hoje a possibilidade de respirar ar puro, de caminhar em contato com a natureza, ou mesmo de levar as crianças para brincar em um ambiente seguro e ao ar livre. No interior de cada lugar, a organização do conjunto, a natureza e a distribuição dos objetos intervêm no uso dos espaços e a eles são conferidos um sentido. Atualmente não se fala mais em 'curar' as doenças da classe operária; se as preocupações higienistas do século XIX perduram, elas assumem novas formas: aquelas do 'bem-estar', do se 'sentir bem' (SERPA, 2007).

Embora haja diferentes conceitos desenvolvidos por diversos autores, tendo como parâmetros várias concepções com enfoque na paisagem, no ambiente como um todo, nos modelos arquitetônicos, os parques verdes urbanos, caracterizados como um elemento dinâmico da cidade é na verdade o que seus cidadãos percebem. 
Entre suas funções, ser um espaço para a socialização da vida urbana cotidiana é a que mais é ressaltada, desde os tempos passados. Num parque as pessoas poderiam caminhar, se encontrar, se conhecer e se relacionar. No início de sua criação era também o espaço de descanso que compensaria as horas de excessivo trabalho por horas de ócio, e é nessa perspectiva que os parques serviriam também para otimizar o trabalho semanal. Vários autores, entre eles Granz (1982) e Kliass (1993), defendem a importância dos parques para a saúde pública e mental, com a busca de um bem-estar psicológico da população, por meio da musicalidade e da organização visual da paisagem.

Nos PVUs, as pessoas podem, por meio das caminhadas e outras atividades esportivas, melhorar suas habilidades sinestésicas corporais. Na sociedade americana, permeada por valores competitivos e individualistas do sistema capitalista, os parques tiveram o papel de reavivar valores relacionados com a vida em comunidade, com a vida do adolescente, do pobre e de grupos étnicos, fazendo dos moradores bons citadinos, com consciência social e o sentimento de democracia (DOBER, 1969).

Cabe ressaltar que, inicialmente os parques eram espaços utilizados pelas classes média e alta, pois eram antigos jardins privados. Entretanto, ao se tornar espaço público, os PVUs passa a se configurar como espaço democrático de socialização aberto a todos os cidadãos independentemente de suas características socioculturais.

O desenvolvimento dos movimentos ambientalistas, que surge no século XX e se acentua nos dias atuais, relata a importância da Educação Ambiental para a formação do cidadão e isto se configura diretamente na função dos parques. Os PVU seriam espaços destinados à construção de uma consciência ecológica, nos quais os cidadãos poderiam compreender os processos naturais, por meio do contato direto com os elementos da natureza, e utilizariam essas informações na conservação dos recursos e do ambiente urbano.

A partir do caminhar histórico da concepção dos parques urbanos, pode-se visualizar que suas funções ainda que modificadas ao logo dos períodos, constituíam espaços de socialização dos diversos visitantes. O PVU como conhecemos hoje, é um elemento típico da grande cidade moderna. Macedo (2003) afirma que estando em um processo constante de decodificação, estes espaços atendem a uma diversidade de solicitação de lazer, tanto esportivas como culturais, não possuindo, muitas vezes, a antiga destinação voltada basicamente para o lazer contemplativo, características dos primeiros grandes parques públicos. Macedo (2003) reconhece que novas funções foram introduzidas nos parques no decorrer do século XX, como as esportivas, as de conservação de recursos naturais, qualidade de vida urbana, entre outras.

Os PVU contribuiriam para melhorar os aspectos físicos e sociais da cidade, por meio da revitalização de espaços abertos, do ordenamento das movimentações, da criação de um sentimento de tranquilidade. Para Cever (1994), é importante na moderna cidade que haja ações no sentido de uma aproximação entre natureza e humanidade. Os problemas da modernidade ocasionaram várias tensões sociais, os espaços verdes poderiam amenizar esses problemas, oferecendo aos citadinos um ambiente agradável, estimulante e acessível. 
Não há consenso sobre a definição de PVU; no entanto, determinados autores citam que se deve levar em conta aspectos como tamanho espacial, presença de vegetação e tipo, e ainda seus objetivos (SCALISE, 2002; SILVA, 2003; CASTELNOU, 2006; OLIVEIRA, 2007; WHATELY et al., 2008). Define-se 'Parque Verde Urbano' como um espaço público urbano, destinado a estabelecer relações sociais de recreação, educação, com intenção de conservação, onde há presença de vegetação com características naturais, não necessariamente originais.

Embora no âmbito acadêmico e de gestão pública se chegue a essas definições, nem sempre estas são compartilhadas pelas pessoas, as quais os PVU seriam potenciais usuárias. O que beneficia o uso social do PVU pelas pessoas que vivem na cidade? Como as pessoas fazem uso desse espaço? Quais as principais funções dos PVU para as pessoas na cidade? Esses questionamentos direcionaram este estudo.

\section{METODOLOGIA}

O estudo é de caráter qualitativo com abordagem descritiva exploratória. Foi desenvolvido em um Parque Verde Urbano, no perímetro urbano de Manaus/AM, sendo um dos mais populares da cidade. Os participantes da pesquisa foram visitantes maiores de 18 anos, sem distinção de gênero, etnia ou cor, que compreendessem a língua portuguesa. A seleção dos participantes foi aleatória, a partir da acessibilidade conferida pelo participante aos pesquisadores. Esse estudo seguiu todos os trâmites éticos para pesquisa com seres humanos.

\section{Lócus da pesquisa}

O Parque do Mindu, Unidade de Conservação do Grupo de Proteção Integral, está localizado no Bairro Parque Dez de Novembro, Zona Centro Sul da cidade de Manaus/AM, com uma área de 46,5ha (Decreto no9043/2007). Foi criado a partir de um movimento popular em 1989, dos moradores do seu entorno, como forma de proteger o habitat do Sauim-de-Manaus, primata que hoje é a mascote da cidade, teve sua fundação no ano de 1992.

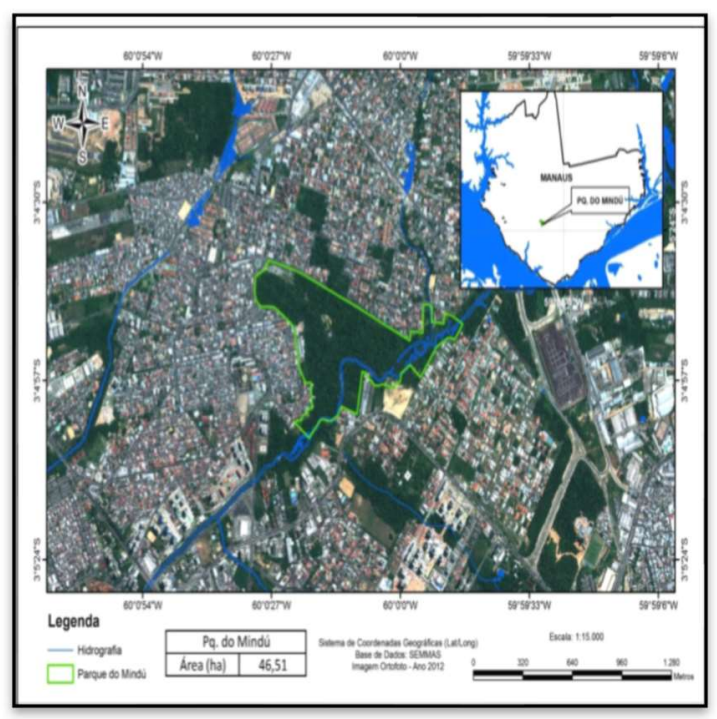

Figura 1: Mapa de localização do Parque Municipal do Mindu. 
De acordo com o decreto de criação, a gestão do Parque Municipal do Mindu, é de responsabilidade da Prefeitura Municipal de Manaus, por meio da Secretaria Municipal de Meio Ambiente e Sustentabilidade - SEMMAS. A SEMMAS constitui o órgão responsável pela criação e implementação da política municipal do meio ambiente e na sua estrutura organizacional dispõe de uma Coordenadoria de Áreas Protegidas, responsável pela criação e gestão das áreas protegidas do município de Manaus, a qual o Parque está vinculado.

A equipe técnica do parque é composta pelo Gestor do Parque, 02 Técnicos administrativos, 01 Bibliotecária, 01 Serviço Social, 08 Agentes de defesa ambiental, 05 Vigilantes ambientais, 01 Bombeiro hidráulico, 03 Serviços gerais e recebe ainda auxilio de estagiários. Além da infraestrutura de gestão interna da SEMMAS, o Mindu, assim como todas as instituições e ações relacionadas à temática ambiental no âmbito municipal, está submetido às normas do Conselho Municipal de Desenvolvimento e Meio Ambiente CONDEMA, órgão colegiado autônomo de caráter consultivo, deliberativo e normativo da política ambiental. Sua estrutura de visitação é composta por biblioteca voltada ao meio ambiente, estacionamento, praças temáticas, orquidário, trilhas pavimentadas e suspensas, sinalização educativa; anfiteatro; centro de atividades e bosque de essências florestais, frutíferas e medicinais/aromáticas.

Podem ser observados, basicamente, quatro ambientes fitoecológicos: floresta densa, área de capoeira, área de campo e área degradada. Sendo que a área de floresta densa tem maior predominância, correspondendo a cerca de $58 \%$ do total da área do parque. Nesses ambientes podem ser encontrados animais que vivem livres na floresta do parque como as preguiças, cutias, pássaros, insetos, macacos entre outros. Encontram-se ainda muitas espécies vegetais típicas da Floresta Amazônica. O objetivo do Mindu é promover e desenvolver atividades ambientais e culturais com a finalidade de propiciar momentos de integração comunitária, permitindo despertar os moradores do entorno e os visitantes para questões socioambientais e culturais no que diz respeito à valorização do mesmo (FONSECA et al,. 2012).

\section{Técnicas e procedimentos}

A pesquisa envolveu a investigação da percepção dos visitantes sobre os espaços naturais e implicações desses espaços para a proteção ambiental e bem-estar social. A perspectiva teórica das Percepções Ambientais (DEL RIO et al., 1999; THIBAUD, 2005; MARIN, 2008; KHUNEN et al., 2011) foi utilizada para compreender a subjetividade presente na relação visitante-parque. Para acessar as Percepções Ambientais, foi utilizado a técnica da entrevista semiestruturada (LAKATOS et al., 1991), aplicada logo após a visita ao parque, cuja gravação de áudio foi transcrita e analisada seguindo o método da análise de conteúdo (BARDIN, 2009). As respostas fechadas foram organizadas em planilha do EXCEL do pacote Microsoft 2007 e posteriormente submetidas a uma análise estatística descritiva de forma a se obter informações sobre outros aspectos. 


\section{Perfil dos participantes}

A pesquisa ocorreu com 30 participantes $(F=22$ e $M=8)$ de 18 a 63 anos de idade. Entre esses participantes 34\% tinha idade entre 18 a 29 anos, $27 \%$ entre 30 e 40 anos, entre as faixas de 41 a 50, 51 a 60 e maiores de $60,13 \%$ cada. Os participantes possuíam níveis escolares variados, sendo que a maioria (56\%) com ensino superior, $17 \%$ superior incompleto, $20 \%$ ensino médio e $7 \%$ ensino fundamental incompleto. Desses, $47 \%$ residiam em Manaus, 23\% eram de cidades do estado do Amazonas e $30 \%$ de outros estados brasileiros. A maioria (65\%) destas pessoas eram empregados, 20\% desempregados, $12 \%$ estudantes e $3 \%$ aposentados.

A característica desses participantes se configura como um público de jovem-adulto, com escolaridade alta, trabalhadores ativos e em sua maioria feminino. Em trabalho desenvolvido por Medeiros et al. (2011) sobre a preferência por ambientes naturais, obteve-se resultado similar ao grupo entrevistado, onde a maioria dos entrevistados era do gênero feminino e constituía-se de maneira geral em um grupo jovem. Vale destacar que conhecer o público e sua faixa etária contribui para o planejamento das atividades a serem desenvolvidas em ambos os parques, assim como é importante verificar o porquê do público idoso ser mais ausente, visto que esta é uma população que cresce no Brasil e por isso deve-se pensar nos variados fatores, como por exemplo, estruturais, que podem facilitar sua visitação.

\section{RESULTADOS E DISCUSSÕES}

\section{O uso social do PVU, frequência de visita e duração}

A forma de uso dos PVUs e o tipo de experiência denotam características que podem identificar um processo de reconhecimento da relação pessoa-ambiente e que nos indica variáveis tanto psicológicas, quanto socioculturais e ambientais. Esse público possui frequências de visita e duração, hábitos e motivos diferenciados. Da mesma forma, esse público desenvolve atividades também distintas nesse lugar.

A frequência de utilização e a apropriação em seu sentido amplo dizem respeito à duração e periodicidade de tempo que os usuários têm disponível, o que pode ser classificado em uso diário, semanal e feriados. Foi observado que, $31 \%$ dos entrevistados, visitava o parque pela primeira vez e $69 \%$ já havia frequentado anteriormente, sendo que $7 \%$ diz visitar uma vez na semana, $27 \%$ ao menos três vezes na semana, $8 \%$ visita uma vez por mês, $19 \%$ ao menos uma vez por ano e $8 \%$ eventualmente. A visita de forma geral é de curta duração, uma vez que $53 \%$ dos entrevistados dizem permanecer no parque por no máximo uma hora, $34 \%$ até 2 horas, $10 \%$ até 3 horas e $3 \%$ mais de 3 horas.

Para Magnoli (1986), é pela relação entre o uso diário e a duração reduzida que se pode observar que são espaços que devem estar próximos da habitação do usuário, sendo, portanto de uso local. Há que se levar em conta o contexto sociocultural amazônico, onde a floresta e os fragmentos florestais apresentamse como paisagem muito presente e próxima dos olhos, mesmo que fora do perímetro urbano, e de forma geral, não apreciada como ambiente de cidade (HIGUCHI et al., 2012; HIGUCHI et al., 2013;). No entanto, os frequentadores são, em sua maioria (60\%), do Estado do Amazonas, e estes dizem frequentar o PVU por se identificarem com sua origem amazônica que concebe a natureza como parte de sua vida, onde vários 
motivos estão conjugados. Além dessa motivação intrínseca, apelos mediáticos atuam para estimular a visita. Nota-se que no período de desenvolvimento desta pesquisa havia uma forte campanha para que a população do entorno, utilizasse o espaço desse parque.

A frequência com que visitantes voltam ao mesmo destino, pode ser um dos indicadores para se levar em conta em programas socioeducativos para proteção do ambiente natural. Quando as pessoas assumem um ambiente como seu, quando sentem que fazem parte daquele ambiente, dificilmente vão querer agredilo. É estabelecida uma relação mais comprometida com os problemas socioambientais da região, e pode servir como instrumento de pressão junto ao poder público para solução de problemas identificados na localidade (LADEIRA et al., 2007).

\section{Hábito e motivo para visitar o Parque}

O hábito de visitar parques verdes é ainda uma atividade pouco presente nas pessoas que vivem em Manaus. No entanto, observa-se a partir no perfil dos participantes, que a maior parte $(60 \%)$ desta são amazonense e há evidências de que esse tipo de deslocamento está em crescimento, no estado, tomando como referência o estudo de Medeiros et al. (2011). Da amostra pesquisada, 50\% não tem hábito de visitar outros PVU como se percebe nessa narrativa: "Não visito outros, porque esse é bem próximo de casa e os outros são muito difíceis de chegar"; 40 \% tem hábito de visitar outros PVU "visito sim, pelo contato com a natureza, pra poder ver a vegetação do lugar, dar sorte de ver algum animal"; e 10\% visita raramente "Raramente porque as atividades diárias me deixam sem tempo".

Barcellos (1999) afirma que do ponto de vista da acessibilidade da população aos parques urbanos, mais importante que a quantidade é a distribuição dos mesmos. Considerando que esses locais devem ter meios de acesso disponíveis e usuais pela população, tais arranjos urbanísticos e de mobilidade são relevantes para facilitar e estimular o hábito de visitas. Junto com o acesso e mobilidade e os significados atribuídos a esse lugar formam um feixe importante para condicionarem o uso, a intensidade e frequência de utilização pelos diferentes segmentos sociais.

Louv (2005) aponta que uma das causas para o afastamento da natureza é o acesso restrito às áreas naturais, ou falta de estimulo e acesso a estes nos centros urbanos. No entanto, essas condições externas não são suficientes, uma vez que suas características de arranjo espacial e paisagístico corroboram para uma unidade indivisível de uso social. Sousa et al. (2012) consideram que as pessoas que visitam um PVU, o fazem com maior frequência por encontrarem nele um espaço que permite um 'deslocamento' da vida cotidiana afim de explorar algo diferente do dia-a-dia atribulado da cidade (FISCHER, 1994)

Vários motivos levam o visitante a se deslocar até o parque, dentre eles 3 motivações principais foram elencadas, sendo, contato com a natureza (50\%), bem-estar e saúde (33\%), e lazer (17\%). O motivo mais citado é aquele da busca por um lugar onde a natureza está presente, nesses lugares as pessoas buscam contemplar a paisagem e estar próximo à natureza. Como já comentado anteriormente, este estudo corrobora com os resultados obtidos por Sousa et al. (2012) quando constatam que o caráter restaurador da natureza está entre os principais motivos da visita a um PVU. 
A maioria (64\%) destas visitas ocorre com a família e $23 \%$ elegem amigos, namorados ou colegas como acompanhantes. Nota-se, portanto, que esses espaços são fundamentais no desenvolvimento de relações sociais no meio urbano, onde se constata uma aproximação principalmente das relações afetivas. Cunha (2002) afirma que esses espaços devem ser ambientes de livre acesso, convívio das relações sociais, além de promover e melhorar a estética da cidade.

\section{Atividades desenvolvidas na visita}

Os PVUs são locais propícios ao desenvolvimento das mais variadas atividades, que podem ser tanto oferecidas pela estrutura do lugar quanto poderá partir da imaginação de seu usuário por meio do que Gibson imortalizou como affordances que este lugar possui (GREENO, 1994). Em outras palavras, as propriedades intrínsecas dos elementos ambientais que no encontro com a percepção do indivíduo, dão surgimento a um tipo de comportamento. A estrutura do local (ambiente cercado com entrada controlada e vigilância) aliada à paisagem natural (árvores frondosas, trilhas na mata e riacho) que os entrevistados relatam um sentimento de segurança e tranquilidade, diferente das ruas da cidade. Todo esse aparato físico contribui para que os frequentadores percebam o local propicio para a visita e maior contato com a natureza.

Entre os entrevistados, 50\% fez trilha pelo parque, buscando conhecer todo espaço, observando a flora e a fauna do lugar. Em trabalho desenvolvido por Dray et al. (2012), foi constado que as trilhas do Mindu possuem grande potencial para receber visitantes, no entanto a falta de guia para grupos pequenos e a manutenção das trilhas, comprometem sua eficácia e o objetivo do parque. Os demais $23 \%$ visitaram o parque objetivando a pratica de atividade previamente programada, seja de exercícios físicos ou simples caminhada. Já $20 \%$ deles diz que observou a paisagem e visitou as áreas temáticas do lugar, como as praças, playground, anfiteatro e o bosque de essências naturais e 7\% ao visitar o parque observou apenas as atrações culturais locais.

Constata-se, portanto, que a intencionalidade das visitas e seu efetivo uso é determinado não apenas pelas motivações do visitante, mas sobretudo pelas condições que esse lugar oferece, considerando as preocupações de segurança e necessidades sociais dos usuários. O uso social decorre de inúmeras variáveis que devem ser levadas em conta na gestão desses espaços e o tipo de atividade que esse lugar estimula.

\section{Percepções ambientais sobre o Mindu e atração pelo lugar}

Os entrevistados foram solicitados a manifestar sua percepção sobre o parque visitado a partir de quatro aspectos: a atração pelo lugar; o pensamento desencadeado durante a visita, sentimentos vivenciados e a importância dado ao espaço verde inserido no ambiente urbano. Cada um desses aspectos apresenta percepções diferenciadas que serão comentadas a seguir.

A atração pelo lugar refere-se a aspectos do lugar que mais chamou sua atenção durante a visita. 0 conjunto de respostas obtidas evidenciou pelo menos três aspectos diferenciados que constituíram categorias de percepção dos sujeitos relacionadas à atração, sendo: a) natureza, b) informação e c) bemestar. 
O posicionamento contemplativo diante de uma paisagem qualquer é o momento em que são revividos ou criados os significados que se atribui aos seus elementos e ao conjunto. É, portanto, uma via interativa que faz o ser humano se desprender de sua referência dominante, seu próprio ser, para perceber o mundo ou perceber-se no mundo (MARIN et al., 2003). Já Kaplan (1987) sugere que a qualidade da interrelação de um sujeito com o ambiente está relacionada às ações inerentes ao indivíduo e aos parâmetros de informação oferecidos pelo ambiente.

A atração do lugar é centrada no que o PVU pode oferecer às necessidades do visitante, e tais necessidades parecem ser primariamente um estado psicológico de equilíbrio das emoções que a vida urbana se encarrega de consumir. Dessa forma, o caráter restaurativo desses espaços devem ser aspectos de maior evidência numa possível campanha para atrair novos visitantes da cidade (SOUSA, 2015).

a) A Natureza: dos participantes visitantes, $80 \%$ se referiram à exuberância da natureza no local, como aspectos que mais Ihes atraiam durante a visita, expressam que são as árvores, a possibilidade de ver animais e a paisagem amazônica como maior atração pelo Parque visitado. Está contido aqui o fato de ter a possibilidade de encontro com a natureza amazônica e poder apreciá-la, sem ser necessário o deslocamento a áreas remotas da mata virgem. Isso pode ser notado nas seguintes expressões: "As arvores, a facilidade de caminhar entre elas, o ambiente natural e o canto das cigarras"; "A exuberância das árvores porque chama atenção por ser amazônico muito diferente do que vemos no Sudeste, é algo inédito";

b) Informação: $10 \%$ dos visitantes são atraídos ao Mindu pela informação disponível nesses lugares. Essa informação inclui desde aspectos científicos acerca do ecossistema, espécimes curiosos e até aspectos socioculturais que ali podem ser vislumbrados: "A dança dos índios que teve no parque eu nunca tinha isto! Até gravei";

c) Bem-Estar: 10\% manifesta se sentirem atraídos ao Mindu devido o bem-estar físico e psicológico proporcionado por esse ambiente natural. As características de tranquilidade emanadas pela floresta e o ar puro são referidos como aspectos que suscitam momentos de agradabilidade ao visitante: "Conforto térmico, pelo fato da floresta ser mais úmida, a temperatura é mais baixa e na cidade está tão quente né?!"; “A beleza, a tranquilidade, o sossego, o calor que é alto lá fora, não tem poluição".

\section{Pensamento desencadeado durante a visita}

Observa-se que o ambiente de um PVU possui elementos importantes tanto para reflexões que atinjam aspectos psicossociais quanto aspectos que possibilitam novas posturas de proteção desses ambientes naturais. Há, portanto uma dupla entrada de ideias que emergem como elementos de transformação do indivíduo em relação a sua própria vida quanto a da natureza. Diferentes estudos apontam para os benefícios proporcionados pela aproximação com a natureza e a relação dessa aproximação com o cuidado ambiental (CORRAL-VERDUGO, 2012; KORPELA, et al., 2010). Vários pensamentos são ativados nesse encontro com os itens físicos existentes no parque. Para os entrevistados esse espaço físico com seus atributos despertou pensamentos: a) de cuidado ambiental (49\%); b) relacional (28\%); e c) existenciais (23\%).

a) Cuidado Ambiental: Ao estar diante da natureza, $49 \%$ dos visitantes diz ser levado a pensar nas questões de preservação e cuidado ambiental, de como as pessoas protegem ou destroem esses ambientes - ecologia. "Faz pensar em preservação, ver essas árvores todas em pé e de repente isso tudo pode sumir"; 
b) Relacional: Para $28 \%$ dos entrevistados o parque o faz pensar nele diante das outras pessoas, família, amigos. "Me remete a minha família, amigos, parentes. Eu morava no interior e isso tudo me faz pensar neles";

c) Existencial: O parque com seus elementos proporciona a $23 \%$ dos visitantes pensar sobre sua vida, suas atitudes do dia a dia, a correria e sua presença no mundo seja ela como um presente divino-introspecção sentido da vida. "Quando eu chego aqui na verdade eu paro de pensar, às vezes eu estou deprimida, triste e quando chego aqui, esqueço tudo. Eu sou privilegiada porque moro perto do parque".

\title{
Sentimentos vivenciados
}

A imersão nesses ambientes do PVU inevitavelmente proporciona sentimentos diferenciados de acordo com as características e experiências dos visitantes. As entrevistas revelaram sentimentos como euforia, alegria, paz, tranquilidade, bem-estar, segurança e outros como melancolia, preocupação com a destruição da natureza e falta de cuidado. Percebe-se que tais sentimentos são ativados a partir da comparação com a vivência na cidade que causa estresse, tristeza entre outros. Desta forma pode-se inferir que o PVU pode despertar sentimentos de: a) Prazer; e b) Pesar.

\begin{abstract}
a) Prazer: $88 \%$ dos entrevistados desenvolveram sentimentos considerados bons de modo geral que proporcionam bem estar, podendo ser expressos usando os termos amor, paz, alegria, felicidade, cuidado. Estes sentimentos são ativados a partir do contato com a natureza presente nesses espaços em oposição ao espaço citadino, como vimos nas falas: "Tranquilidade, tem bichos, animais, aqui a gente consegue ver e ouvir, é um ambiente sem estresse, cobrança, sem computador"; "Liberdade, eu nasci na mata, agora moro na cidade é completamente diferente, se você não quiser ficar preso tem que sair dela, aqui não... é um pedacinho da minha liberdade lá";

b) Pesar: Refere-se aos sentimentos de melancolia diante de uma realidade externa que os envergonha e entristece, e os colocam num estado de indignação por ter cada vez menos espaços que preservam a natureza. Os sentimentos de pesar foram manifestados por $12 \%$ dos entrevistados, eles são despertados diante de aspectos que remetem à degradação, a perda da natureza nativa e a massiva antropização que acompanha o crescimento das cidades. "Não foi um sentimento bom, principalmente ao ver o igarapé, senti desprezo por essa sociedade que não dá o devido valor, não tem uma educação ambiental adequada, e os governos que também não tem a preocupação adequada com a natureza".
\end{abstract}

\section{Importância do espaço verde na cidade}

O conjunto destas percepções sobre o PVU revela a necessidade de reaproximação do homem com ambientes naturais e a consequente necessidade de proteção desses lugares. Constata-se que a percepção ambiental dos visitantes incorpora de forma contundente aspectos ambientais que levam ao bem-estar e estes aspectos socioambientais dão suporte ao caráter de importância do PVU.

Dessa forma, os espaços se configuram como instrumentos de proteção ambiental e sensibilização das pessoas frente aos problemas ambientais gerados pela urbanização das cidades, tanto nos aspectos sociais quanto ambientais. Os visitantes percebem o espaço de formas distintas, no entanto todos os entrevistados acreditam que o PVU é fundamental na cidade porque são: a) espaços que permitem o contato com a natureza; b) oferecem qualidade ambiental; e c) interação social.

a) Contato com a natureza: para 50\% dos entrevistados o espaço é importante por oferecer ao homem urbano contato com a natureza, podendo despertar o sentimento de cuidado, preservação e conscientização da necessidade de proteger o ambiente. "Sim porque quem 
vive na cidade não está acostumado a ver, sempre tem ruas, barulhos e estes locais mostram como é estar em sintonia com a natureza"; "Sim, porque coloca as pessoas que tem essa vida urbana com esse lado mais natural, a paisagem, o meio ambiente, a gente se enxerga em algo maior";

b) Qualidade Ambiental: Para 28\% o parque verde é importante por possibilitar o conforto térmico, "oxigênio puro" e bem-estar no ambiente citadino, é visto como um ponto de fuga. "Sim, porque cria um espaço de lazer necessário, a dimensão de uma qualidade de vida. Você vem pra cá, você descansa, distrai, respira um ar puro, traz a questão da saúde, de uma higiene ambiental, intelectual, acho que tudo isso contribui mais também com a educação dos jovens".

c) Interação Social: para $22 \%$ o espaço é importante por propiciar aos visitantes uma forma de lazer e vivencia com a família e amigos, além de ofertar conhecimento tanto ambiental quanto cultural. "Sim, pela educação ambiental, transmissão do conhecimento e oportunidade do contato com a família"; "Sim, pra gente passear, ter pra conhecer. Ai pra fora tem muita coisa, as pessoas aproveitam para se reunir".

\section{CONCLUSÕES}

Ao ser criado um PVU, tenta-se dar um significado multifuncional ao espaço, mas estes critérios só se consolidam com a efetiva participação da sociedade para a qual ele foi criado. Alguns aspectos são revestidos de maior ou menor saliência, os quais dependem do contexto físico e social que estão inerentes ao uso dado a qualquer ambiente. A acessibilidade do parque é um fator importante para que frequentadores e visitantes busquem esse contato com a natureza, bem-estar e lazer. Estes espaços são fundamentais no desenvolvimento de relações sociais no meio urbano, onde se constata uma aproximação principalmente das relações familiares, desde que alguns critérios sejam observados, tais como a atratividade do lugar, a paisagem estética, os recursos naturais presentes, a segurança e mobilidade permitida.

O estudo mostrou que a principal motivação para visitação desse espaço está relacionada com a natureza. Esse ambiente natural presente no PVU, possibilita o despertar de sentimentos de sensibilização frente as questões ambientais e estes percebem a importância da conservação ambiental para a manutenção destes ambientes na cidade. Conjugado com a proximidade ao lugar de moradia, o PVU pode se tornar um espaço de vivências habituais e de conforto psíquico e social.

O conjunto das especificidades de uso social e percepção ambiental sobre o PVU, permitiu verificar ainda, que apesar deste estudo envolver em sua maioria pessoas da própria cidade e região amazônica, onde no imaginário comum as pessoas estão em constante contato com a natureza e pouco parecem procurar por ela na cidade, há uma necessidade iminente destes espaços que funcionem como escape em relação ao estresse que essa urbanidade provoca. Além disso, esses espaços possibilitam maior sensibilização com as questões ambientais e a importância de protegermos a natureza diante da poluição e desgaste de ambientes naturais.

Esse estudo problematiza, por fim a importância dada ao PVU devido seu potencial para novos hábitos e novos comportamentos relacionados à saúde física, emocional e ambiental. No entanto, outros estudos são necessários para aprofundamento do entendimento dos cuidados que promovam a apropriação do espaço pelo usuário, de maneira que os frequentadores de PVU se sintam verdadeiramente sensibilizados 
com suas causas socioambientais e reflitam sobre atitudes de proteção ambiental, que perdurem para além do momento da visitação.

Apesar das limitações próprias desse estudo, ficou evidente como áreas naturais no ambiente citadino promove uma gama de benefícios como os ecológicos e constituem espaço de socialização e restauro psicossocial. Por isso merecem maior cuidado do poder público, seja na sua manutenção, ou, no seu planejamento como lugar de visitação. Estes espaços possuem dimensões relevantes e natureza exuberante que andam por um fio.

\section{REFERÊNCIAS}

BARCELLOS, V. Q.. Os Parques como espaços livres públicos de lazer: o caso de Brasília. Tese (Doutorado em Arquitetura) - Universidade de São Paulo, São Paulo, 1999.

BARDIN, L.. Análise de Conteúdo. Lisboa: Almedina, 2009.

BROWNE, K.; WHITAKER, B.. Parks for people. New York: Schocken Books, 1973.

CASTELNOU, A. M. N.. Parques Urbanos de Curitiba: de espaços de lazer a objetos de consumo. Cadernos de Arquitetura e Urbanismo, Belo Horizonte, v.13, n.14, p.5373, 2006.

CEVER, F. A.. A World of environmental design (Urban Sapaces). Barcelona: Streetsand Squares, 1994.

COSTA, L. A.; HIGUCHI, N.;PINHEIRO JÚNIOR, J. R.; GOMES, L. N.. Avaliação das Áreas Verdes Públicas da Cidade de Manaus: situação em 1991. Caminhos de Geografia, Uberlândia, v.6, n.9, p.1-10, 2006

CORRAL-VERDUGO, V.. Sustentabilidad y Psicologia Positiva: uma visión optmista de las conductas proambientales y prosociales. Cidade do Mexico: Manual Moderno, 2012.

CUNHA, R. D. A.. Os usos, funções e tratamentos das áreas de lazer da área central de Florianópolis. Tese (Doutorado em Engenharia de Produção) - Universidade Federal de Santa Catarina, Florianópolis, 2002.

DRAY, W. T.; SIMONETTI, S. R.. As Trilhas Interpretativas do Parque do Mindu em Manaus - AM: utilização e conservação. SEMINÁRIO DE PESQUISA EM TURISMO DO MERCOSUL, 7. Anais. Caxias do Sul: UCS, 2012.

DEL RIO, V.; OLIVEIRA, L.. Percepção Ambiental: a experiência brasileira. São Carlos: EDUFSCar, 1999

DOBER, R. P.. Environmental Design. New York: Von Nostrand Runhold Company, 1969.

FISCHER, G.. Psicologia Social do Ambiente. Lisboa: Instituto Piaget, 1994.

FONSECA, R.; COSTA, L. A.; TELLO, J. C. R.; MEDEIROS. C. M. Estudo de Caso do Corredor Ecológico e Urbano do Mindu: mapeamento de passivos ambientais do Parque Municipal do Mindu, Manaus-Am. REVSBAU, Piracicaba, v.7, n.2, p.1-9, 2012.
GARCIA, S.. Sustentabilidade Ambiental Parque Urbano Monte Calvário. Tandil: Universidad Nacional del Centro de la Província de Buenos Aires, 2005.

GARCIA, S.; GUERREIRO, M.. Indicadores de Sustentabilidad Ambiental em La Gestión de Espacios Verdes. Parque Urbano Monte Calvario, Tandil, Argentina. Revista de Geografia Norte Grande, Santiago, n.35, p.45-57, 2006.

GRANZ, G.. The Politics of Park Desing: A History of Urban Parks in America. London: The Mit Press, 1982.

GREENO, J. G.. Gibson's Affordances. Psychological Review, v.101, n.2, p.336-342, 1994

HIGUCHI, M. I. G.; AZEVEDO, G. C.; FORSBERG, S. S.. A Floresta e sociedade: ideias e práticas históricas. In: HIGUCHI, M. I. G.; HIGUCHI, N.. A floresta amazônica e suas múltiplas dimensões: uma proposta de educação ambiental. 2 ed. Manaus: 2012. p.311-357.

HIGUCHI, M. I. G.; SILVA, K.. Entre a floresta e a cidade: percepção do espaço social de moradia em adolescentes. Psicologia para América Latina, v.25, p.5-23, 2013.

HIGUCHI, M. I. G.; CALEGARE, M.. Percepções sobre a floresta amazônica, áreas verdes e manejo ambiental. In: HIGUCHI, M. I. G.; FREITAS, C. C.; HIGUCHI, N.. Morar e viver em Unidades de Conservação no Amazonas: considerações socioambientais para os planos de manejo. Manaus: 2013

KAPLAN, S.. Aesthetics, affect, and cognition. Environment and Behavior, v.19, n.1, p.3-32, 1987.

KLIASS, R. G.. Parques Urbanos de São Paulo. São Paulo: Pini, 1993.

KORPELA, K. M.; YLEN, M.; TYRVAINEN, L.; SILVENNOINEN, $\mathrm{H}$.. Favorite green, waterside and urban environments, restorative experiences and perceived health in Finland. Health Promotion International, v.25, n.2, p.200-209, 2010 DOI: http://doi.org.10/1093/heapro/daq007

KUHNEN, A.; HIGUCHI, M. I. G.. Percepção Ambiental. In: CAVALCANTE, S.; ELALI, G. A.. Temas básicos em Psicologia Ambiental. Petrópolis: Vozes, 2011.

LADEIRA, A.; RIBEIRO, G.; DIAS, H.; GONÇALVES, C.; SCHAEFER, R.; FILHO, E.; OLIVEIRA, A.. O perfil dos visitantes 
do Parque Estadual Ibitipipoca (PEIb), Lima Duarte - MG

Árvore, v.31, n.6, p.1091-1098, 2007.

LAKATOS, E. M.; MARCONI, M.. Fundamentos da

Metodologia Científica. 3 ed. São Paulo: Atlas, 1991.

LOUV, R.. Last child in the woods: saving our children from nature-deficit disorder. Chapel Hill: Algonquim Books of Chapel Hill, 2005.

MACEDO, S. S.. Parques Verdes Urbanos no Brasil. 2 ed. São Paulo: EDUSP, 2003.

MAGNOLI, M. M.. O Parque no desenho Urbano. In: SEMINÁRIO SOBRE DESENHO URBANO NO BRASIL, 2. Anais. Rio de Janeiro: CNPq, 1986.

MARIN, A. A.; OLIVEIRA, H.; COMAR, V.. A Educação Ambiental num contexto de complexidade do campo teórico da percepção. INCI, v.28, n.10, p.616-619, 2003.

MARIN, A. P.. Pesquisa em educação ambiental e percepção ambiental. Pesquisa em Educação Ambiental, v.3, n.1, p.203-222, 2008.

MEDEIROS, J. S.; HIGUCHI, M. I. G.. Preferência por ambientes naturais. Manaus: INPA, 2011.

MEUNIER, I. M. J.. Percepções e Expectativas de Moradores do Grande Recife - PE em Relação ao Parques Urbanos. REVSBAU, Piracicaba, v.4, n.2, p.35-43, 2009.

OLIVEIRA, L. A.; MASCARÓ, J. J.. Análise da qualidade de vida urbana sob a ótica dos espaços públicos de lazer. Ambiente Construído, Porto Alegre, v.7, n.2, p.59-69, 2007.

OLIVEIRA, P. T.. Sistemas de Indicadores Ambientais: um modelo para o monitoramento de Parques Verdes Urbanos. Dissertação (Mestrado em Tecnologia Ambiental) - Instituto de Pesquisa e Tecnologia do Estado de São Paulo, São Paulo, 2007.
RIBEIRO, M. A.. Ecologizar: pensando o ambiente humano. Belo Horizonte: Rona, 2000.

ROMERO, M. A. B.. Desempenho das constantes morfológicas: índices de adequação ambiental na periferia do Distrito Industrial. In: PAVIANI, A.. Brasília: gestão urbana: conflitos e cidadania. Brasília: EDUNB, 1999. p.85110.

SCALISE, W.. Parques Urbanos: evolução, projeto, funções e usos. Revista Assentamentos Humanos, Marília, v.4, n.1, p.17-24, 2002.

SEGAWA, H.. Ao amor do público: jardins no Brasil. São Paulo: FEPESP, 1996.

SERPA, A.. O espaço público na cidade contemporânea. São Paulo: Contexto, 2007

SILVA, L. J. M.. Parques Urbanos: a natureza na cidade: uma análise da percepção dos atores urbanos. Dissertação (Mestrado em Gestão e Política Ambiental) - Universidade de Brasília, Brasília, 2003.

SOUSA, A. L.. A floresta na porta e na janela: percepções sobre o lugar de trabalho em um fragmento florestal urbano. Dissertação (Mestrado em Psicologia) Universidade Federal do Amazonas, Manaus, 2015.

SOUSA, A. L.; HIGUCHI, M. I. G.. A percepção da paisagem do Bosque da Ciência. Manaus: INPA, 2012.

THIBAUD, J. P.. Psicologia Ambiental e Política Ambiental: estratégias de construção do futuro. São Paulo: EDUSP, 2005.

WHATELY, M.; SANTORO, P. F.; GONÇALVES, B. C.; GONZATTO, A. M.. Parques urbanos municipais de São Paulo: subsídios para a gestão. São Paulo: Instituto Socioambiental, 2008. 